\title{
Retrieval of well-learned propositional rules: Insensitive to changes in activity of individual neurotransmitter systems?
}

\author{
MARTIN SARTER \\ Ohio State University, Columbus, Ohio
}

\begin{abstract}
On the basis of the visual conditional discrimination paradigm, a procedure has been developed that forces rats to retrieve propositional rules from reference memory (e.g., flashing light, go left; constant light, go right). Using operant boxes, rats were trained to perform a conditional visual (successive) discrimination task (go/go) on an FR10 schedule of reinforcement. During the first trial of a day's test session, incorrect responding did not result in the termination of the trial. The ratio between correct and incorrect leverpresses until completion of the FR10 at the correct lever on this first trial was considered a measure of the rat's ability to retrieve the correct rule. During the subsequent trials of a test session, incorrect responses led to the termination of the trial. Behavioral measures from this stage of a day's session were considered as an indication of behavioral performance. Scopolamine $(0.1,0.39$, or $1.56 \mathrm{mg} / \mathrm{kg})$ did not affect retrieval but impaired all measures of performance. Chlordiazepoxide $(3.0,5.0$, or $10.0 \mathrm{mg} / \mathrm{kg}$ ) similarly spared retrieval abilities but disrupted performance at the highest dose. Baclofen (1.56, 3.13, or $4.69 \mathrm{mg} / \mathrm{kg}$ ) nonspecifically disrupted responding at the highest dose. Amphetamine $(0.3,0.56$, or $1.0 \mathrm{mg} / \mathrm{kg}$ ) generally reduced the number of correct responses. Thus, none of these treatments specifically interfered with the retrieval of information about well-learned stimulus-response rules. It is hypothesized that the retrieval of these rules is comparable with the automatic and implicit reactivation of nondeclarative information in humans, or even with priming. Furthermore, it seems likely that this process shows multiple neuronal representations and, therefore, remains widely insensitive to manipulations in individual neurotransmitter systems.
\end{abstract}

In contrast to the research on learning, the psychobiology of memory retrieval processes has been relatively ignored. In other words, "there has persisted the dominant perspective that the critical processes responsible for variance in behavioral plasticity take place during the learning episode (encoding, attention, association) rather than at the time of expression (retrieval, performance)" (Spear, Miller, \& Jagielo, 1990, p. 171; see also Spear, 1971). This seems surprising, considering the intensely discussed hypotheses that memories are permanent and potentially retrievable (Freud, 1924; Loftus \& Loftus, 1980), and that amnesia is a result of the failure to retrieve information (Miller \& Springer, 1973; but see Gold \& King, 1974; Squire, 1982).

In experiments aimed at determining the biological substrates of retrieval from reference memory, the experimental manipulation typically takes place before the retest. However, pretest manipulations are likely to affect nonmemory components such as locomotor, emo-

I am grateful to $P$. Dudchenko for his comments on this manuscript. This research was funded in part by grants from the Office of Research and Graduate Studies, Ohio State University (No. 221184), the Cognitive Science Center, Ohio State University, and the Ohio State Department of Aging (No. 723079). Correspondence should be addressed to Martin Sarter, Department of Psychology, 27 Townshend Hall, Ohio State University, Columbus, $\mathrm{OH} 43210$. tional, and motivational variables (McGaugh, 1989; see the discussions in Santucci, Kanof, \& Haroutunian, 1989, and Quartermain \& Altman, 1982). Furthermore, in the event that the pretest manipulation impairs retrieval, (non-)state-dependent mechanisms may account for the subject's inability to retrieve the information. Pretest drug administration may provide a set of "internal stimulus events" (Spear, 1971) that may interfere with the processing of normal retrieval cues. Thus, retrieval test procedures that indicate that the (treated) animal is (still) familiar with the principal behavioral components and response requirements of the task will drastically enhance the validity of interpretations of results in terms of retrieval mechanisms.

In this study, the principles of the conditional visual discrimination paradigm were employed, in order to develop a procedure for measuring retrieval from reference memory. The study was also aimed at identifying neurochemically defined brain systems that are crucially involved in the retrieval processes. As described below, the animals learned an appetitive go-left/go-right conditional visual discrimination on an FR 10 schedule of reinforcement (see the Method section). It was planned to restrict the interpretation of the effects of a pharmacological treatment on retrieval in this task to the following events: (1) It seems likely to assume that, following the delivery of the first reinforcer during the first trial of a session, the 
animal's accuracy in selecting subsequent levers is no longer exclusively based on the retrieval of information about the stimulus-response rules from reference memory. In other words, while, at the beginning of a daily session, the animal's selection of a lever is entirely dependent on the retrieval of the rules from reference memory, the correct selection of levers subsequent to the first reward may additionally profit from information obtained by the outcome of the preceding trials. Therefore, the performance during the initial trial of a daily session was considered to reflect the ability of the animal to retrieve the stimulus-response rules from reference memory. This is a more restrictive interpretation of the task than that made by Everitt et al. (1987), who generally considered the performance in a conditional visual discrimination task (on an FRl schedule of reinforcement) as a measure of reference memory. (2) However, an effect of a treatment on the animal's accuracy during the initial trial would not be interpreted in terms of retrieval if the subsequent performance was also significantly affected. In this event, it cannot be excluded that the effects on retrieval were confounded by mechanisms other than the retrieval from reference memory (i.e., motor and sensorimotor functions).

Four drugs that modulate the activity of major transmitter systems, and that have been assumed to be involved in the retrieval of information from reference memory, were selected. (1) The antimuscarinic scopolamine was proposed by Deutsch (1971) to interfere only minimally with the retrieval of older memories but to disrupt recent memory. Human studies have largely confirmed this hypothesis (Beatty, Butters, \& Janowski, 1986; Huff, Mickel, Corkin, \& Growdon, 1988). However, in rats, scopolamine has been found to impair working memory delay-independently, without affecting analogous discrimination performance. Spencer, Pontecorvo, and Heise (1985) concluded on the basis of a series of experiments that scopolamine may (also) affect retrieval of response rules from reference memory. (2) The indirect dopamine agonist amphetamine has been proposed to lower the activation threshold for old memories (Wise \& Stein, 1970). In passive avoidance tasks, pretest amphetamine increased response latencies, which was considered as evidence for facilitated retrieval (Quartermain \& Altman, 1982). (3) Although benzodiazepine receptor agonists (BZRa) such as chlordiazepoxide have been demonstrated to interfere primarily with the acquisition of new information and with discriminative abilities (see, e.g., Cole, 1986; Francis \& Cooper, 1979), some studies have pointed to the possibility that BZRa generally affect the evaluation and the functional processing of previously learned stimuli (Ljungberg, Lidfors, Enquist, \& Ungerstedt, 1987; Sarter \& Stephens, 1988; Stephens \& Sarter, 1988). Such a mechanism would suggest that BZRa impair the retrieval of stimulus-response rules, especially in a situation that requires the subject to retrieve competing response alternatives. (4) The $G_{A B A}$ agonist baclofen has been demonstrated to interfere with memory in animal studies
(Castellano, Brioni, Nagahara, \& McGaugh, 1989; Swartzwelder, Tilson, McLamb, \& Wilson, 1987). In addition, in humans, evidence for an effect on memory of familiar names has been reported (Sandyk \& Gillman, 1985). The latter finding prompted the question of whether baclofen exerts specific effects on retrieval of normally well-remembered knowledge. In addition to the pharmacological experiments, we carried out a test on spontaneous forgetting, in order to obtain an indication of the retention following long periods of discontinued training.

\section{METHOD}

\section{Subjects}

The subjects were 8 male Sprague-Dawley rats weighing $250-300 \mathrm{~g}$ at the beginning of the pharmacological experiments. They were housed individually in a temperature and humiditycontrolled environment on a 12:12-h light:dark schedule. Water was freely available, and limited access to food was given after each daily session to maintain body weight at $85 \%$ free-feeding weight.

\section{Apparatus}

An operant system (MedAssociates, East Fairfield, VT) was used. It consisted of eight operant boxes, each one equipped with retractable levers; three panel lights $(2.8 \mathrm{~W})$; a houselight $(2.8 \mathrm{~W})$; and a food-pellet dispenser. Based on an interface equipped with modules providing eight TTL logic level outputs and inputs, an $1800+$ Everex computer, and a 16-port interface card, the system was completely automated. The OPN software (Spencer \& Emmett-Oglesby, 1985) was used in order to control the operant boxes and to record the behavioral data.

\section{Procedure}

Initially, the animals were shaped to press the levers in order to receive food reinforcement $(45 \mathrm{mg}$, Noyes, Lancaster, $\mathrm{NH}$ ). Subsequently, a go-left/go-right conditional discrimination was trained. The discriminanda were a flashing light $(0.1-\sec$ pulses at $5.0 \mathrm{~Hz})$ and a light constantly turned on. The stimuli were presented at the central panel light. The trial began with either constant light or a flashing light presented for $10 \mathrm{sec}$. A correct response resulted in the delivery of a food pellet and the onset of a variable intertrial interval $(5 \pm 1.5 \mathrm{sec})$. An incorrect response or an error of omission resulted in a longer intertrial interval $(15 \pm 3 \mathrm{sec})$ and no reinforcement. An equal number of rats were trained on flashing light, go left/constant light, go right, and on the alternative combinations. In contrast to the procedure in Everitt et al. (1987), the levers were not retracted during the intertrial intervals, because we had found previously that the animals became pseudoconditioned to the lever movements, which markedly interfered with the acquisition of the conditional discrimination.

Once the animals learned this task, the rate of reinforcement was successively decreased (FR4, FR7, FR10), and a correct response was reinforced with two food pellets. The final task, which consisted of the initial retrieval test and the subsequent performance test, proceeded in the following way: After an adaption period of $5 \mathrm{~min}$, the central panel light was turned on to display either constant light or a flashing light (random order over sessions/days). This first stimulus presentation, which represented the retrieval test, terminated after the animal pressed the correct lever 10 times, resulting in the delivery of two food pellets (the first one immediately, the second one $2 \mathrm{sec}$ later). Incorrect leverpresses did not terminate the trial. The completion of 10 correct leverpresses was followed by a variable intertrial interval $(5 \pm 1.5 \mathrm{sec})$ plus a fixed time interval of $5 \mathrm{sec}$. Afterward, the performance trials took place, where a randomly selected sequence of the discriminanda was presented 
(10 presentations per stimulus; each stimulus was presented for $30 \mathrm{sec}$ ). Correct responding (FR10) was reinforced by two pellets, and a response on the incorrect lever or a failure to fulfill the schedule within $30 \mathrm{sec}$ resulted in the termination of the trial and the onset of an intertrial interval $(15 \pm 5 \mathrm{sec})$ plus a fixed time interval of $5 \mathrm{sec}$. Following completion of the session, the levers were retracted. A daily session lasted maximally $45 \mathrm{~min}$ (see Figure 1 for a schematic illustration of the principles of the task).

\section{Behavioral Measures}

From the retrieval test at the beginning of a daily session, the percent lever operations on the correct lever (\% correct ${ }_{\text {ret }}$ ) was calculated. This measure was considered to reflect the rats' ability to retrieve the discrimination rule. In addition, response latencies were recorded $\left(t_{\text {ret }}\right)$. From the subsequent performance test, the percent correct responses (\% correct $t_{\text {per }}$ ) and the response latencies ( $\left.t_{\text {per }}\right)$ were recorded. In the event that an animal did not respond during the performance test, the $t_{\text {per }}$ was defined as $30 \mathrm{sec}$ (the maximal duration of the presentation of a stimulus). Finally, the number of leverpresses during the fixed time intervals that followed all variable intertrial intervals was recorded (ITI $I_{\text {per }}$ ). In post hoc analyses, the effects of amphetamine and scopolamine on performance were further analyzed by inspecting the effects of the treatments on performance trials terminated by incorrect responses and on trials that were not completed (omissions).

\section{Drug Treatments}

All treatments were given in accordance with a randomized sequence of drugs and doses. Testing was carried out 7 days a week, between $10 \mathrm{a} . \mathrm{m}$. and noon. Drug treatments were followed by 1 or more vehicle-treatment days, until the animals returned to baseline performance. Maximally three drug doses were tested during 7 days. On the average, subsequent drug treatments were separated by two vehicle treatments. The following types of drugs, doses, vehicles, and time periods between the administration of the drug and the beginning of the behavioral tests were used. Scopolamine Hbr (Sigma), muscarinic antagonist: $0.1,0.39,1.56 \mathrm{mg} / \mathrm{kg}$; i.p.; saline; 30 min. Chlordiazepoxide (Sigma), benzodiazepine receptor full agonist: $3.0,5.0,10.0 \mathrm{mg} / \mathrm{kg}$; i.p.; saline; $30 \mathrm{~min}$. Baclofen

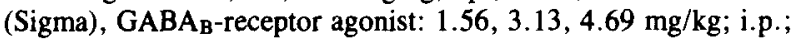
saline; $20 \mathrm{~min}$. D-amphetamine sulfate (Sigma), indirect dopamine receptor agonist: $0.30,0.50,1.0 \mathrm{mg} / \mathrm{kg}$; s.c.; saline; $30 \mathrm{~min}$.

\section{Data Analyses}

The effects of the drug treatments on the behavioral measures described above were analyzed, using Friedman's repeated measures ANOVA on each drug treatment. The interdependency of the behavioral measures was not taken into account. For each statistical test, the values for the vehicle conditions were determined by calculating the medians of the values from the vehicle sessions that preceded the drugged sessions. In the event that the ANOVA indicated significant group differences, multiple group comparisons were carried out using Wilcoxon's matched-pairs signed-ranks test.

\section{Spontaneous Forgetting}

The training of animals was discontinued for $2,3,6,10$, or 16 days. Following each test, the animals were retrained for at least 3 days/sessions or until they regained baseline performance during two consecutive sessions. Retrieval and performance data were analyzed, using Friedman's repeated measures ANOVA.

\section{RESULTS}

\section{Baseline Performance}

As indicated in Table 1, all lever operations during the first trials were carried out on the correct levers. The animals took between 0.53 and $0.82 \mathrm{sec}$ (medians) for a single lever operation. During subsequent trials (where incorrect lever operations terminated the trial), the animals performed between $72 \%$ and $82 \%$ correct responses, the response latencies varied between 0.64 and $0.76 \mathrm{sec}$ (medians), and the animals performed between 26.5 and 39.5 leverpresses during the 5 -sec periods that were part of the variable intertrial intervals.

\section{Spontaneous Forgetting}

Even when the animals were not trained up to 16 days, they showed complete retrieval of the rules required to select the correct levers (see Table 1 ). The only significant effect was found on the ITI $I_{\text {per }}$ measure that followed 3 days of discontinued training.
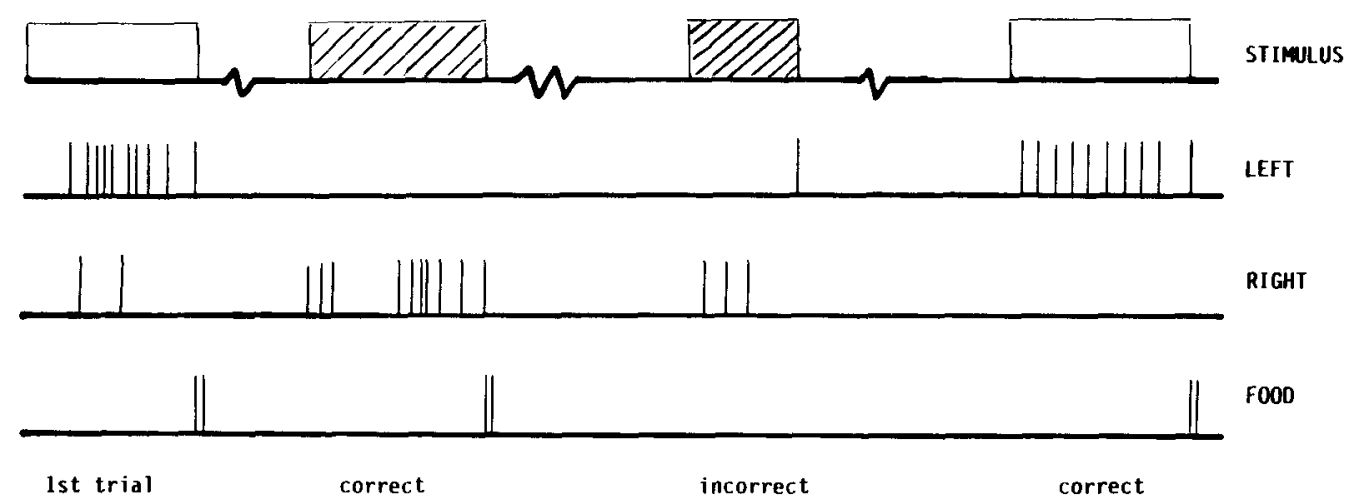

Figure 1. Schematic illustration of the task used in this experiment. Two alternative stimuli were successively presented (open and striped boxes) and separated by a variable intertrial interval. The rules underlying the present example would require the animal to press the left lever 10 times in order to receive two reinforcements whenever the constant light (indicated by the open box) was presented at the central panel light. Upon presentation of the flashing light (striped box), the right lever would be correct. The diagram indicates that during the first trial (the retrieval test), incorrect responses did not result in the termination of the trial. As is illustrated schematically for the third stimulus presentation, during subsequent trials (the performance test), incorrect responses did result in the termination of the trial (for details, see the Method section). 


\section{Scopolamine}

During the retrieval tests, scopolamine did not significantly affect the \% correct ret $_{\text {measure but increased the }}$ time the animals took to respond. During subsequent trials, scopolamine reduced the number of successfully completed trials. A more detailed inspection of the performance data (by post hoc analyses; see Figure 2) sug- gests that both an increase in incorrect responding and in the number of not-completed trials contributed to this effect. However, scopolamine did not significantly increase either the number of trials terminated by incorrect responses $\left(\chi^{2}=6.94, p=.07\right)$ or the number of trials that were not completed during $30 \sec \left(\chi^{2}=6.17, p=\right.$ $.10)$. Scopolamine reduced responding during the fixed

Table 1

Effects of Discontinuation of the Behavioral Training, of Scopolamine, Chlordiazepoxide, Baclofen, and Amphetamine on Retrieval and Performance of a Visual Conditional Discrimination Task

\begin{tabular}{|c|c|c|c|c|c|}
\hline \multicolumn{6}{|c|}{ Spontaneous Forgetting } \\
\hline Days & $\%$ Correct $_{\text {ret }}$ & $t_{\text {ret }}$ & $\%$ Correct $_{\text {per }}$ & $t_{\text {per }}$ & $\mathrm{ITI}_{\text {per }}$ \\
\hline 0 & 100 & 0.59 & 75 & 0.62 & 24 \\
\hline 2 & 83.3 & 0.65 & 77.5 & 0.60 & 23 \\
\hline 3 & 100 & 0.70 & 65 & 0.73 & $17^{*}$ \\
\hline 6 & 90.9 & 1.01 & 82.5 & 0.71 & 27 \\
\hline 10 & 100 & 0.81 & 65 & 0.82 & 20 \\
\hline 16 & 100 & 0.52 & 67.5 & 0.53 & 41 \\
\hline$x^{2}$ & 8.23 & 5.94 & 4.94 & 8.01 & 14.28 \\
\hline$p$ & 0.14 & 0.31 & 0.42 & 0.16 & 0.01 \\
\hline
\end{tabular}

\begin{tabular}{|c|c|c|c|c|c|}
\hline \multicolumn{6}{|c|}{ Pharmacological Effects } \\
\hline Dose $(\mathrm{mg} / \mathrm{kg})$ & $\%$ Correct $_{\text {ret }}$ & $t_{\text {ret }}$ & $\%$ Correct per & $t_{\text {per }}$ & $\mathrm{ITI}_{\text {per }}$ \\
\hline \multicolumn{6}{|c|}{ Scopolamine } \\
\hline vehicle & 100 & 0.53 & 80.0 & 0.74 & 31.0 \\
\hline 0.1 & 100 & $0.85^{*}$ & $50.0^{*}$ & 2.18 & $17.0^{*}$ \\
\hline 0.39 & 84 & $1.50^{*}$ & $30.0^{*}$ & 3.67 & $12.5^{*}$ \\
\hline 1.56 & 87 & $1.71^{*}$ & $5.0^{*}$ & $6.47^{*}$ & $7.5^{*}$ \\
\hline$\chi^{2}$ & 4.68 & 10.5 & 11.19 & 11.25 & 8.66 \\
\hline$\hat{p}$ & 0.20 & 0.01 & 0.01 & 0.01 & 0.03 \\
\hline \multicolumn{6}{|c|}{ Chlordiazepoxide } \\
\hline vehicle & 95.5 & 0.77 & 72.5 & 0.64 & 39.5 \\
\hline 3.0 & 90.9 & 1.23 & 67.5 & 0.80 & $19.5^{*}$ \\
\hline 5.0 & 100 & 1.11 & 65.0 & 1.10 & 18.5 \\
\hline 10.0 & 57.2 & $2.53 *$ & $0.0^{*}$ & $19.20^{*}$ & $3.0^{*}$ \\
\hline$\chi^{2}$ & 6.71 & 10.95 & 14.88 & 16.8 & 12.86 \\
\hline$\stackrel{\lambda}{p}$ & 0.08 & 0.01 & 0.00 & 0.00 & 0.00 \\
\hline \multicolumn{6}{|c|}{ Amphetamine } \\
\hline vehicle & 100 & 0.61 & 80.0 & 0.71 & 26.5 \\
\hline 0.3 & 100 & 0.76 & 75.0 & 0.72 & 26.5 \\
\hline 0.56 & $77.3^{*}$ & $1.56^{*}$ & 65.0 & 0.60 & 26.0 \\
\hline 1.0 & $55.6^{*}$ & $2.12 *$ & 65.0 & 1.06 & 25.5 \\
\hline$\chi^{2}$ & 9.75 & 8.1 & 11.29 & 6.6 & 1.09 \\
\hline$\hat{p}$ & 0.02 & 0.04 & 0.049 & 0.09 & 0.78 \\
\hline \multicolumn{6}{|c|}{ Baclofen } \\
\hline vehicle & 100 & 0.75 & 72.5 & 0.69 & 29.5 \\
\hline 1.56 & 100 & 0.58 & 62.5 & 0.99 & 25.5 \\
\hline 3.13 & 83.9 & 1.61 & 62.5 & 1.71 & 10.5 \\
\hline 4.69 & $50.0^{*}$ & $369.50^{*}$ & $0.0^{*}$ & $30.00^{*}$ & $0.0^{*}$ \\
\hline$\chi^{2}$ & 8.81 & 7.95 & 13.31 & 14.51 & 12.80 \\
\hline$\hat{p}$ & 0.03 & 0.04 & 0.00 & 0.00 & 0.00 \\
\hline
\end{tabular}

Note-\% correct ret $=$ percent lever operations on the correct lever from the retrieval test; $t_{\text {ret }}=$ response latencies. $\%$ correct $_{\text {per }}=$ percent correct trials on the performance test; $\mathrm{t}_{\mathrm{per}}=$ response latencies; $\mathrm{ITI}_{\mathrm{per}}=$ number of leverpresses during fixed time intervals that followed all variable intertrial intervals. The values indicate medians. The chi-square values and the $p$ values indicate the results of the repeated measures ANOVA. *Significantly different to the vehicle-treated controls; Wilcoxon test, $p<.05$ (post hoc comparisons; see the Method section). 

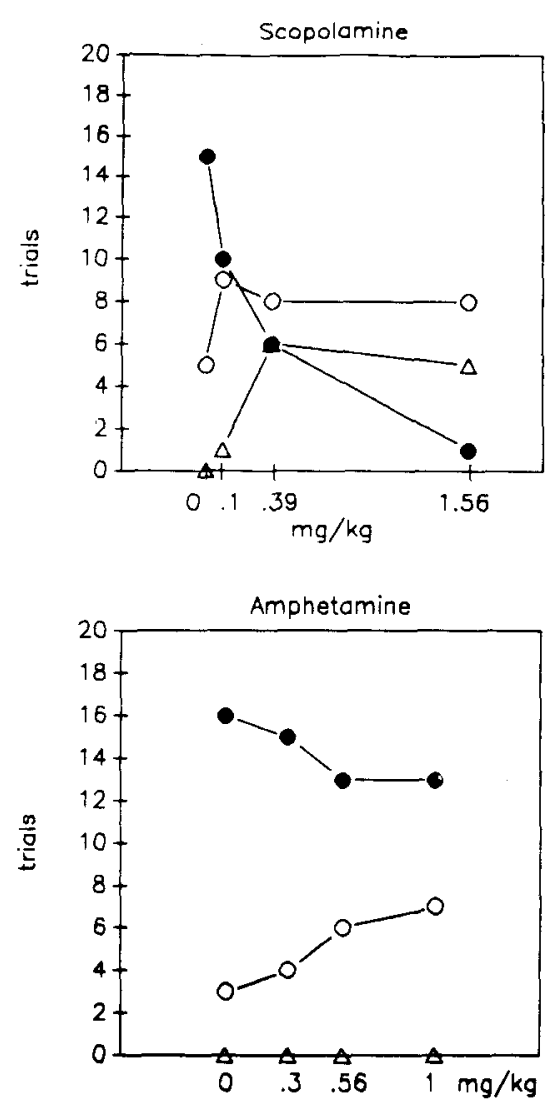

- number of trials completed

- O number of trials termincted by incorrect response $\Delta-\Delta$ number of trials not completed

Figure 2. Results of post hoc analyses on the effects of scopolamine and amphetamine on performance. The graphs show the effects of the treatments on the number of trials correctly completed (and, therefore, rewarded), on the trials that were terminated because of an incorrect response, and on the number of trials that were not completed within $30 \mathrm{sec}$ (medians; the total number of trials given was 20). Following scopolamine, the reduction in the number of completed trials was a result of an increase in both incorrect and disrupted responding. Amphetamine produced an increase in incorrect responding rather than in incomplete responding (i.e., not fulfilling the FR10 schedule). However, none of the treatments produced a significant effect on incorrect or incomplete responding individually.

part of the intertrial interval and increased response latencies during the trials subsequent to the first one (see Table 1).

\section{Chlordiazepoxide}

Similarly to scopolamine, chlordiazepoxide did not significantly affect the \% correct ret $_{\text {measure. At the highest }}$ dose of chlordiazepoxide, all measures of performance indicated behavioral disruption.

\section{Amphetamine}

Amphetamine dose-dependently increased the number of incorrect lever operations and the response latencies during all trials. Multiple comparisons did not reveal differences between the $\%$ correct $_{\text {per }}$ values between individual doses. Post hoc analyses suggested that the reduction in the number of completed trials was a result of an increase in the number of incorrect responses rather than in errors of omission (see Figure 2). However, neither measure was affected significantly (number of trials terminated by incorrect responses, $\chi^{2}=5.6, p=.13$; number of not-completed trials, $\chi^{2}=0.85 ; p=.84$ ).

\section{Baclofen}

At the highest dose $(4.69 \mathrm{mg} / \mathrm{kg})$, baclofen disrupted performance and resulted in an impairment of all behavioral measures. At this dose, the majority of the animals did not complete the first trial (i.e., they did not fulfill the requested 10 operations on the correct lever), so that data from subsequent trials were not available.

\section{DISCUSSION}

\section{Automatic Retrieval of Procedural Knowledge and Spontaneous Forgetting}

Vehicle-treated animals demonstrated perfect retrieval of the constant-light/flashing-light-go-left/go-right stimulus-response rules, even following 16 days without training. This result prompted the question of the type of information and the level of cognitive processing underlying performance in this task.

As Everitt et al. (1987) pointed out, the ability to perform a visual conditional discrimination task requires more complex principles than Pavlovian association learning and may involve the capacity to learn and to retrieve propositional rules. The attempt to determine the level of processing in retrieving such rules remains a matter of speculation, and such an effort is not possible without some minimal assumptions about the mental state of the subject (Tulving, 1985).

It can be proposed that the information which was retrieved by the animals in this experiment be categorized as procedural memory. The critical issue here is whether previous experience changed the way the subject was responding to the environment, "without affording access to the specific instances that led to this change" (Squire, 1982, p. 260). Furthermore, one can assume that this procedural knowledge can be automatically activated by a stimulus and that this process does not need a "central executive" (automatic processing; see Cowan, 1988; this is "implicit memory" as defined by Schacter, 1985).

One can further speculate that the almost perfect ability of vehicle-treated animals to retrieve the stimulusresponse reinforcement associations in this task, even after 16 days without training, was based on several conditions given in the present experiment. First, the animals were forced to retrieve information in a situation that provided a complete set of contextual and reminder cues (see Deweer, Sara, \& Hars, 1980; Sara \& Deweer, 1982) or, in different terms, of associated response and memory attributes (Spear, 1971). Second, the implicit or automatic 
reactivation (Spear et al., 1990) of procedural information appears to represent a cognitive process quite insensitive to behaviorally or neuronally induced manipulations of the animals' status. Third, the overtraining of the animals and the FR10 schedule of reinforcement (Mackintosh, 1974) could be assumed to contribute to the perfect performance found even after 16 days without training. It seems likely that the FR10 schedule of reinforcement eventually became a unit of responding. Although such an effect may have contributed to the finding that the animals did not tend to switch between levers, there is no reason to expect that it contributed to the selection of the correct lever. Finally, the fact that the present task involved a go/go principle was presumably supporting the perfect performance, because in a go/no-go version of such a task, the animals' need to selectively inhibit responding would require additional steps of stimulus processing (Warburton, 1977).

We have recently found that well-trained rats were unable to learn the reversal of the rules underlying a conditional discrimination (Dudchenko \& Sarter, 1990). This result contrasts with the rats' ability to acquire simple position discrimination reversals (Spear, 1971; Stephens, Weidmann, Quartermain, \& Sarter, 1985). It may be speculated that the stimulus-response associations underlying the conditional discrimination task are processed on a cognitive level comparable to presemantic priming in humans (Tulving \& Schacter, 1990), at least in overtrained animals (see also the discussion in Izquierdo, 1989). The reactivation of the conditional rules by the rats in the present experiment may be comparable to the animals' ability to select one out of multiple levers in drugdiscrimination experiments. These assumptions on the level of the cognitive processing of rats performing a conditional discrimination may have important impacts on the interpretation of the effects of neuronal manipulations on the performance in such tasks (see, e.g., Everitt et al., 1987).

\section{Scopolamine}

Scopolamine did not affect performance during the first trial (retrieval test), but correct responding during subsequent testing was drastically impaired. This result corresponds widely with the conclusions from studies on the effects of scopolamine in intact humans and patients with Alzheimer's disease (Huff et al. 1988), and partly with the animal literature (Spangler, Chachich, \& Ingram, 1988). However, in several studies of humans and of animals, it has been demonstrated that scopolamine administered before the retest of a previous learning experience impairs performance (Beatty \& Bierley, 1986; Petersen, 1979; Ridley, Bowes, Baker, \& Crow, 1984). Although relatively long delays (up to $24 \mathrm{~h}$ ) between the learning and the retrieval test were used in these studies, the designs of the experiments and the type of information to be retrieved suggest that the abilities addressed were unrelated to the retrieval of well-learned rules or of procedural memory (see also the discussion in Beatty \& Bierley, 1986).

The selective effect of scopolamine on correct responding during trials subsequent to the first trial supports the basic idea underlying the present experiment-that performance during the first trial is based on processes different from those involved in subsequent task performance. More specifically, the fact that scopolamine did not affect selection of the correct lever during the first trial (but during subsequent trials) may support the idea that performance in the first trial represents a measure of the retrieval from reference memory.

In accordance with the hypothesis formulated above about the level of cognitive processing of well-trained rats in the conditional discrimination task are findings that indicate that scopolamine does not affect priming in humans (Tulving \& Schacter, 1990). It may generally be assumed that this nonconscious form of memory is quite insensitive to context changes (Riccio, Richardson, \& Ebner, 1984), including drug-induced changes in the state of subjects.

\section{Chlordiazepoxide}

Overall, there is a qualitative correspondence between the effects of scopolamine and chlordiazepoxide-that is, no effect on retrieval but an effect on subsequent performance. This correspondence indirectly supports evidence suggesting that some of the behavioral effects of benzodiazepine receptor ligands are mediated via cholinergic systems (Sarter, Bruno, \& Dudchenko, 1990; Sarter, Schneider, \& Stephens, 1988; Sarter \& Stephens, 1988).

An effect of chlordiazepoxide on retrieval was not to be expected, since, in animals and in humans, benzodiazepine receptor agonists do not affect this type of processing and have even been shown to exert beneficial effects (retrograde enhancement; Cahill, Brioni, \& Izquierdo, 1986; Fang, Hinrichs, \& Ghonheim, 1987). However, the high baseline performance of the animals in the present experiment did not allow the detection of retrograde enhancement.

\section{Baclofen}

At the highest dose tested, baclofen generally disrupted the animals' behavior (Table 1). The smaller doses did not affect any behavioral measure (see also Sidel, Tilson, McLamb, Wilson, \& Swartzwelder, 1988). Thus, there is no evidence from this experiment that the effects of baclofen specifically interfere with memory.

\section{Amphetamine}

During the first trial, amphetamine reduced correct responding and increased response latencies. Subsequently, amphetamine reduced the number of completed trials, primarily by increasing the number of incorrect responses (Figure 2; Rech, Borsini, \& Samanin, 1984). In accordance with the criteria for an interpretation of an effect in terms of retrieval (see the introduction to the 
present paper), it cannot be concluded that amphetamine specifically interfered with the retrieval of stimulusresponse rules. Because, however, the extent of the effects of amphetamine on correct responding differed between the first and the subsequent trials (Table 1), further post hoc analyses were carried out on the behavioral components of this result.

Due to the nature of the procedures used to record data in this experiment, the recorded data files from the first trials do not provide the possibility to determine the sequence of correct and incorrect responses. Therefore, there is no directly available evidence that might indicate that amphetamine-induced switching (Evenden \& Robbins, 1983; Robbins \& Watson, 1981), or perseverative or stereotypic responding (Harvey, 1987; Rebec \& Bashore, 1984; Ridley et al., 1981) represented the basis for the increase in the number of incorrect responses. However, if amphetamine had produced such effects during the first trials, subsequent trials would have been similarly affected.

Table 2 lists the numbers of sequential and nonsequential errors for individual animals. In addition, the sequential errors were divided into sequential errors made by staying at the incorrect lever while a stimulus was presented repeatedly (failure to switch) and into sequential errors made by switching while the stimulus changed. The latter situation required the animal to stay at the (formerly incorrect) lever, because, following the presentation of the alternative stimulus, responding to this lever was correct (failure to stay).

Amphetamine $(1.0 \mathrm{mg} / \mathrm{kg})$ seemed to result in an increase in the number of sequential errors (post hoc test, using Wilcoxon's test, $p=.067$ ). However, neither switching (see failure to stay) nor perseverative responding (see failure to switch) represented an exclusive basis for the increase in the number of sequential errors. There-

Table 2

Effects of Amphetamine (1.0 mg/kg) on Different Types of Errors

\begin{tabular}{|c|c|c|c|c|c|c|c|c|}
\hline \multirow[b]{3}{*}{ Animal } & \multirow{2}{*}{\multicolumn{2}{|c|}{$\begin{array}{l}\text { Nonsequential } \\
\text { Errors }\end{array}$}} & \multirow{2}{*}{\multicolumn{2}{|c|}{$\begin{array}{c}\text { Sequential } \\
\text { Errors }\end{array}$}} & \multicolumn{4}{|c|}{ Failure to } \\
\hline & & & & & \multicolumn{2}{|c|}{ Switch } & \multicolumn{2}{|c|}{ Stay } \\
\hline & $\mathrm{V}$ & D & $\mathrm{V}$ & $\overline{\mathrm{D}}$ & $\bar{v}$ & D & $\mathrm{V}$ & $\mathrm{D}$ \\
\hline 1 & 2 & 4 & 0 & 3 & 0 & 2 & 0 & 1 \\
\hline 2 & 2 & 2 & 0 & 0 & 0 & 0 & 0 & 0 \\
\hline 3 & 5 & 4 & 3 & 3 & 2 & 0 & 1 & 3 \\
\hline $4^{*}$ & 0 & - & 0 & - & 0 & - & 0 & - \\
\hline 5 & 3 & 2 & 0 & 4 & 0 & 1 & 0 & 3 \\
\hline 6 & 4 & 4 & 1 & 2 & 0 & 1 & 1 & 1 \\
\hline 7 & 3 & 6 & 1 & 7 & 1 & 3 & 0 & 4 \\
\hline 8 & 1 & 3 & 0 & 0 & 0 & 0 & 0 & 0 \\
\hline Medians & 3 & 4 & 0 & 3 & 0 & 1 & 0 & 1 \\
\hline
\end{tabular}

Note-Nonsequential errors $=$ number of incorrect responses that were not preceded by a trial similarly terminated by incorrect response. Sequential errors $=$ number of incorrect responses that were in sequence. Failure to switch = number of sequential errors during successively repeated presentations of a stimulus, thus requiring the animal to shift for correct responding. Failure to stay $=$ number of sequential errors during a change of the presented stimulus, thus requiring the animal to stay for correct responding. $\mathrm{V}=$ vehicle. $\mathrm{D}=$ amphetamine $1.0 \mathrm{mg} / \mathrm{kg}$. *Animal 4 did not reach the performance stage following the treatment with amphetamine. fore, our data do not support the possibility that amphetamine produced such effects in this task. Finally, there is no reason to assume that amphetamine disrupted discriminative abilities (Andrews \& Holtzman, 1988). Thus, the data do not provide a clear performance-related explanation for the amphetamine-induced decrease in correct responding. Although it cannot be excluded that this result was related to an amphetamine-induced increase in response competition (Lyon \& Robbins, 1975), or to an impairment in executing behavioral sequences (Ljungberg \& Enquist, 1987) or in attentional abilities (Grilly, Gowans, McCann, \& Grogan, 1989), it can be hypothesized that an interference with retrieval processes contributed to the amphetamine-induced reduction in correct responding.

Such a speculation would be in direct opposition to the result found by Sara and Deweer (1982), that amphetamine enhanced retrieval after a long retention interval. However, an inspection of the data of Sara and Deweer (1982) suggests that the basis of the facilitatory effects of amphetamine remains unsettled. ${ }^{1}$ The fact that haloperidol was also reported to facilitate retrieval in a similar type of experiment (Sara, 1986) may support the view that the effects of amphetamine on retrieval of information remain unclear.

\section{Multiple Neuronal Representation \\ of Procedural Knowledge}

Weiskrantz and Warrington (1979) demonstrated that classical conditioning of an eye-blink response can be acquired and adequately retained by amnesic patients. Since then, it has been demonstrated that amnesics are able to learn even more complex tasks such as a stimulus sequence in a serial reaction time task (Nissen \& Bullemer, 1987), and they have displayed practice effects on the Tower of Hanoi puzzle (Cohen, Eichenbaum, Decado, \& Corkin, 1985; see also Parkin, 1982). It is becoming evident that the complexity of nondeclarative abilities that may be retained by amnesic patients (Benzing \& Squire, 1989; Hirst \& Volpe, 1984) has been previously underestimated (see also the example given by Crystal, Grober, \& Masur, 1989).

Although the clinical findings suggest that the neuronal representation of procedural memory is organized in a highly redundant manner and/or in lower subcortical structures (Markowitsch, 1985), some authors (Benzing \& Squire, 1989) have proposed that nondeclarative memory may be intrinsic to cortical and extrapyramidal motor systems. The results of these experiments do not support the idea that an individual neurotransmitter system is crucially involved in the processing of nondeclarative memory, and thus they do not advocate a localizationist hypothesis.

\section{Complexity of Effects of Neuronal Manipulations Versus Differentiation Between Effects on Retrieval and Performance}

There seems to be an obvious dilemma in differentiating between pharmacological effects on retrieval and per- 
formance, and the variety of interdependent cognitive and noncognitive effects of psychopharmacological treatments. The criteria defined in the present experiment for an interpretation of an effect on retrieval (especially Criterion 2; see the introduction) may be inappropriate with respect to the almost imperative induction of memoryunrelated effects by systemically administered psychopharmacological treatments. The significance of this dilemma may depend on the level of analysis of neuronal mechanisms of cognitive processes and on the species tested. In searching for the neuronal mechanisms of retrieval processes in rats, a focus on neuronal subgroups, subcircuits, and so forth, may therefore represent a more productive research strategy.

\section{REFERENCES}

ANDREws, J. S., \& Holtzman, S. G. (1988). Effects of d-amphetamine, morphine, naloxone, and drug combinations on visual discrimination in rats. Psychopharmacology, 94, 172-177.

BeAtTY, W. W., Bierley, R. A. (1986). Scopolamine impairs encoding and retrieval of spatial working memory in rats. Physiological Psychology, 14, 82-86.

Beatty, W. W., Butters, N., Janowski, D. S. (1986). Patterns of memory failure after scopolamine treatment: Implications for cholinergic hypotheses of dementia. Behavioral \& Neural Biology, 45, 196-211.

Benzing, W. C., \& Suure, L. R. (1989). Preserved learning and memory in amnesia: Intact adaption-level effects and learning of stereoscopic depth. Behavioral Neuroscience, 103, 538-547.

CAHILl, L., Brioni, J., \& IzQuierdo, I. (1986). Retrograde memory enhancement by diazepam: Its relation to anterograde amnesia, and some clinical implications. Psychopharmacology, 90, 554-556.

Castellano, C., Brioni, J. D., Nagahara, A. H., MCGaugh, J. L. (1989). Post-training systemic and intra-amygdala administration of the GABA-B agonist baclofen impairs retention. Behavioral \& $\mathrm{Neu}$ ral Biology, 52, 170-179.

Cohen, N. J., Eichenbaum, H., Decado, B., \& Corkin, S. (1985). Different memory systems underlying the acquisition of procedural and declarative knowledge. Annals of the New York Academy of Sciences, 444, 54-71.

COLE, S. O. (1986). Effects of benzodiazepines on acquisition and performance: A critical assessment. Neuroscience \& Biobehavioral Reviews, 10, 265-272.

CoWAN, N. (1988). Evolving conceptions of memory storage, selective attention, and their mutual constraints within the human information-processing system. Psychological Bulletin, 104, 163-191.

Crystal, H., Grober, E., \& Masur, D. (1989). Preservation of musical memory in Alzheimer's disease. Joumal of Neurology, Neurosurgery, \& Psychiatry, 52, 1415-1416.

DEUTSCH, J. A. (1971). The cholinergic synapse and the site of memory. Science, 174, 788-794.

Deweer, B., Sara, S. J., \& Hars, B. (1980). Contextual cues and memory retrieval in rats: Alleviation of forgetting by a pretest exposure to background stimuli: Animal Learning \& Behavior, 8 , 265-272.

DUDChENKo, P., \& SARTER, M. (1990). [Reversing propositional rules]. Unpublished raw data.

EVENDEN, J. L., \& RoBbins, T. W. (1983). Increased response switching, perseveration and perseverative switching following damphetamine in the rat. Psychopharmacology, 80, 67-71.

Everitt, B. J., Robbins, T. W., Evenden, J. L., Marston, H. M., Jones, G. H., \& SIRKIÄ, T.E. (1987). The effects of excitotoxic lesions of the substantia innominata, ventral and dorsal globus pallidus on the acquisition and retention of a conditional visual discrimination: Implications for cholinergic hypotheses of learning and memory. Neuroscience, 22, 441-469.
Fang, J. C., Hinrichs, J. V., \& Ghonheim, M. M. (1987). Diazepam and memory: Evidence for spared memory function. Pharmacology, Biochemistry \& Behavior, 28, 347-352.

FrancIs, R. L., \& CoOper, S. J. (1979). Chlordiazepoxide-induced disruption of discrimination behaviour: A signal detection analysis. Psychopharmacology, 63, 307-310.

FreUd, S. (1924). Notiz über den "Wunderblock." In A. Mitscherlich, A. Richards, \& J. Strachey (Eds.), Sigmund Freud Studienausgabe: Vol. 3. Psychologie des Unbewußten (pp. 363-369). Frankfurt: S. Fischer.

GoLD, P. E. \& King, R. A. (1974). Retrograde amnesia: Storage failure versus retrieval failure. Psychological Review, 81, 465-469.

Grilly, D. M., Gowans, G. C., MCCann, D. S., Grogan, T. W (1989). Effects of cocaine and d-amphetamine on sustained and selective attention in rats. Pharmacology, Biochemistry \& Behavior, 33, 733-739.

HARVEY, J. A. (1987). Behavioral pharmacology of central nervous system stimulants. Neuropharmacology, 26, 887-892.

HiRsT, W., \& VolPE, B. T. (1984). Automatic and effortful encoding in amnesia. In M. S. Gazzaniga (Ed.), Handbook of cognitive Neuroscience (pp. 369-386). New York: Plenum.

Huff, F. J., Mickel, S. F., Corkin, S., \& Growdon, J. H. (1988). Cognitive functions affected by scopolamine in Alzheimer's disease and normal aging. Drug Development Research, 12, 271-278.

IZQUIERDo, I. (1989). Different forms of post-training memory acquisition. Behavioral \& Neural Biology, 51, 171-202.

LJUNGBERG, T., \& ENQUiST, M. (1987). Disruptive effects of low doses of d-amphetamine on the ability of rats to organize behaviour into functional sequences. Psychopharmacology, 93, 146-151.

LJUNGBERG, T., LIDForS, L., ENQUIST, M., \& UNGERSTEDT, U. (1987). Impairment of decision making in rats by diazepam: Implications for the "anticonflict" effects of benzodiazepines. Psychopharmacology, 92, 416-423.

LofTus, E. F., \& LofTus, G. R. (1980). On the permanence of stored information in the human brain. American Psychologist, 35, 409-420.

LyoN, M., \& RoBbins, T. (1975). The action of central nervous system stimulant drugs: A general theory concerning amphetamine effects. In W. B. Essman \& L. Valzelli (Eds.), Current developments in psychopharmacology (Vol. 2, pp. 80-163). New York: Spectrum.

MaCkintosh, N. J. (1974). The psychology of animal learning. London: Academic Press.

MarkowitsCH, H. J. (1985). Hypotheses on mnemonic information processing by the brain. International Journal of Neuroscience, 27. 191-227.

MCGAuGH, J. L. (1989). Involvement of hormonal and neuromodulatory systems in the regulation of memory storage. Annual Review of Neuroscience, 12, 255-287.

Miller, R. R., \& SPRINGER, A. D. (1973). Amnesia, consolidation, and retrieval. Psychological Review, 80, 69-79.

NisSEN, M. J., \& Bullemer, P. (1987). Attentional requirements of learning: Evidence from performance measures. Cognitive Psychology, 19, 1-32.

PARKIN, A. J. (1982). Residual learning capability in organic amnesia. Cortex, 18, 417-440.

Petersen, R. C. (1979). Scopolamine state-dependent processes in man. Psychopharmacology, 64, 309-314.

Quartermain, D., \& Altman, H. J. (1982). Facilitation of retrieval by d-amphetamine following anisomycin-induced amnesia. Physiological Psychology, 10, 283-292.

RebeC, G. V., BASHORE, T. R. (1984). Critical issues in assessing the behavioral effects of amphetamine. Neuroscience \& Biobehavioral Reviews, 8, 153-159.

Rech, R. H., Borsini, F., \& Samanin, R. (1984). Effects of damphetamine and d-fenfluramine on performance of rats in a food maze. Pharmacology, Biochemistry \& Behavior, 20, 489-493.

Riccio, D. C., Richardson, R., \& Ebner, D. L. (1984). Memory retrieval deficits based upon altered contextual cues: A paradox. Psychological Bulletin, 96, 152-165.

Ridley, R. M., Bowes, P. M., BAKer, H. F., \& Crow, T. J. (1984). An involvement of acetylcholine in object discrimination learning and memory in the marmoset. Neuropsychologia, 22, 253-263. 
Ridley, R. M., Haystead, A. J., Baker, H. F. (1981). An analysis of visual object reversal learning in the marmoset after amphetamine and haloperidol. Pharmacology, Biochemistry \& Behavior, 14, 345-351.

Robbins, T. W., Watson, B. A. (1981). Effects of d-amphetamine on response repetition and win-stay behaviour in the rat. In $\mathrm{C}$. $\mathbf{M}$. Bradshaw, W. Szabadi, \& C. F. Lowe (Eds.), Quantification of steadystate operant behavior (pp. 441-444). Amsterdam: Elsevier.

Sandyk, R., \& Gillman, M. A. (1985). Baclofen-induced memory impairment. Clinical Neuropharmacology, 8, 294-295.

Santucci, A. C., Kanof, P. D., Haroutunian, V. (1989). Effect of physostigmine on memory consolidation and retrieval processes in intact and nucleus basalis-lesioned rats. Psychopharmacology, 99. 70-74

SaRA, S. J. (1985). Noradrenergic modulation of selective attention: Its role in memory retrieval. Annals of the New York Academy of Sciences, 444, 178-193.

SARA, S. J. (1986). Haloperidol facilitates memory retrieval in the rat. Psychopharmacology, 89, 307-310.

SaRA, S. J., \& DeweER, B. (1982). Memory retrieval enhanced by amphetamine after a long retention interval. Behavioral \& Neural Biology, 36, 146-160.

Sarter, M., Bruno, J. P., \& Dudchenko, P. (1990). Activating the damaged basal forebrain cholinergic system: Tonic stimulation versus signal amplification. Psychopharmacology, 101, 1-17.

Sarter, M., Schneider, H. H., \& Stephens, D. N. (1988). Treatment strategies for senile dementia: Antagonist $\beta$-carbolines. Trends in Neuroscience, 11, 13-17.

SARTER, M., STEPHENS, D. N. (1988). $\beta$-carbolines as tools in memory research: Animal data and speculations. In I. Hindmarch \& $\mathbf{H}$. Ott (Eds.), Benzodiazepine receptor ligands, memory and information processing (pp. 230-245). Berlin: Springer.

SCHACTER, D. L. (1985). Multiple forms of memory in humans and animals. In N. M. Weinberger, J. L. McGaugh, \& G. Lynch (Eds.), Memory systems of the brain (pp. 351-379). New York: Guilford.

Sidel, E. S., Tilson, H. A., Mclamb, R. L., Wilson, W. A., SWartzWelder, H. S. (1988). Potential interactions between GaBAb and cholinergic systems: Baclofen augments scopolamine-induced performance deficits in the eight-arm radial maze. Psychopharmacology, 96, $116-120$

Spangler, E. L., Chachich, M. E., \& Ingram, D. K. (1988). Scopolamine in rats impairs acquisition but not retention in a 14-unit $\mathrm{T}$-maze. Pharmacology, Biochemistry \& Behavior, 30, 949-955.

SPEAR, N. E. (1971). Forgetting as retrieval failure. In W. K. Honig \& P. H. R. James (Eds.), Animal memory (pp. 46-109). New York: Academic Press.

Spear, N. E., Miller, J. S., \& Jagielo, J. A. (1990). Animal memory and learning. Annual Review of Psychology, 41, 169-211.

Spencer, D. G., Jr., Emmett-Oglesby, M. W. (1985). Parallel processing strategies in the application of microcomputers to the behavioral laboratory. Behavior Research Methods, Instruments, \& Computers, 17, 294-300.

Spencer, D. G., JR., Pontecorvo, M. J., Heise, G. A. (1985). Central cholinergic involvement in working memory: Effects of scopolamine on continuous nonmatching and discrimination performance in the rat. Behavioral Neuroscience, 99, 1049-1065.
Squire, L. L. (1982). The neuropsychology of human memory. Annual Review of Neuroscience, 5, 241-273.

StePhens, D. N., \&ARTER, M. (1988). Bidirectional nature of benzodiazepine receptor ligands extends to effects on vigilance. In I. Hindmarch \& H. Ott (Eds.), Benzodiazepine receptor ligands, memory, and information processing (pp. 205-217). Berlin: Springer.

Stephens, D. N., Weidmann, R., Quartermain, D. , Sarter, M (1985). Reversal learning in senescent rats. Behavioural Brain Research, 17, 193-202.

Swartzwelder, H. S., Tilson, H. A., Mclamb, R. L., Wilson, W. A. (1987). Baclofen disrupts passive avoidance retention in rats. Psychopharmacology, 92, 398-401

Tulving, E. (1985). On the classification problem in learning and memory. In L. G. Nilsson \& T. Archer (Eds.), Perspectives on leaming and memory (pp. 67-94). Hillsdale, NJ: Eribaum.

Tulving, E., SChacter, D. L. (1990). Priming and human memory systems. Science, 247, 301-306.

Warburton, D. M. (1977). Stimulus selection and behavioral inhibition. In L. L. Iversen, S. D. Iversen, \& S. H. Snyder (Eds.), Drugs, neurotransmitters, and behavior (pp. 385-431). New York: Plenum.

Weiskrantz, L., Warrington, E. K. (1979). Conditioning in amnesic patients. Neuropsychologia, 17, 187-194.

Wise, C. D., Stein, L. (1970). Amphetamine: Facilitation of behavior augmented release of norepinephrine from the medial forebrain bundle. In E. Costa \& S. Garattini (Eds.), Amphetamine and related compounds (pp. 463-485). New York: Raven Press.

\section{NOTE}

1. Sara and Deweer's (1982) report did not indicate a statistically significant difference between the performance of the animals during the last acquisition trial and the saline-treated animals during the test 3 weeks later (see their Experiment 1, p. 149, and their Figure 1). Therefore, the significance of the statement that the "control animals showed significant forgetting"' (p. 146) remains unclear. Furthermore, they used a six-unit spatial discrimination task (see Figure 1 in Sara, 1985). Because the chance probability of an error for each of the six decisions is 0.5 , one would expect that complete random behavior results in three errors. The mean number of errors at the beginning of the training (their Figure 1), however, was six ( $p=.015$; binominal test, calculated by this author), and for the last acquisition session two $(p=.23)$. In order to understand the reported error rates, it seems necessary to assume that the animals frequently returned to boxes visited already, and that retracing errors therefore represented a substantial part of the total number of errors. Since the results do not provide a differentiation between different types of errors, the basis for the facilitatory effect of amphetamine remains unsettled. One possibility is that amphetamine reduced the number of errors made following returns to previously visited boxes (retracing errors), or that amphetamine reduced the total number of returns. However, such effects would unlikely be a result of the facilitation of retrieval. It should be noted that haloperidol was also reported to facilitate retrieval in a similar experiment (Sara, 1986).

(Manuscript received June 21, 1990; revision accepted for publication August 13, 1990.) 